\title{
Time Variation of Parameters Related to the Accelerating Preshock Crustal Deformation in the Aegean Area
}

\author{
G. F. Karakaisis ${ }^{1}$, A. S. Savvaidis ${ }^{1}$, and C. B. Papazachos ${ }^{1}$
}

\begin{abstract}
The time variation of two parameters related to accelerating seismic deformation before strong earthquakes in the Aegean area is examined. The first is the $b$ parameter of the Gutenberg-Richter relation and the second is the curvature parameter $C$, which is a measure of deviation of the accelerating preshock deformation from a linear time variation of this deformation. Following two different procedures, it was found that the $b$ value exhibits a decreasing trend prior to the oncoming earthquake, in agreement with the results of laboratory experiments and other independent observations. $C$ values also show a decreasing trend before main shocks. These results indicate that such time variations of these parameters can be considered as precursory phenomena of ensuing strong earthquakes.
\end{abstract}

Key words: Accelerating seismicity, $b$ value, curvature parameter $C$, Aegean area.

\section{Introduction}

Accumulated observational evidence on the time variation of intermediate magnitude seismicity, studies on the behavior of the seismic activity during a seismic cycle and recently proposed relative models suggest accelerating crustal deformation before large earthquakes. During the last four decades a number of scientists noted changes in the rate of moderate-sized earthquakes before and after great earthquakes in several regions (Tocher, 1959; Mogi, 1969; RAleigh et al., 1982; KeILIS-BoroK et al., 1988; KNOPOFF et al., 1996). FEDOTOv (1968) studying smaller earthquake occurrence frequency between large plate boundary events in the Kamchatka-Kurile region, was perhaps the first to describe a seismic cycle. The seismic cycle concept was further examined in several other studies (MogI, 1977, 1981; SCHOLZ, 1988, 1990; KARAKAISIS et al., 1991).

Recently, seismic activation has been recognized in association with an increase in seismicity that occurred prior to several strong earthquakes in California (SYKES and JAume, 1990; Bufe and VArnes, 1993; BufE et al., 1994). Certain patternrecognition earthquake prediction algorithms are mainly based on long-distance correlation and seismic activation (KeILIS-BoroK, 1990). TRIEP and SyKes (1997)

\footnotetext{
${ }^{1}$ Geophysical Laboratory, School of Geology, Univ. of Thessaloniki, Greece. E-mail: karakais@geo.auth.gr
} 
studying strong earthquakes with $M \geq 7.0$ in Asia found a high seismicity rate prior to the 1950 Himalayan event ( $M=8.6)$. SORNETTE and SORNETTE (1990) suggested that the generation of the accelerating moderate magnitude seismicity can be considered as a critical phenomenon culminating in a large event considered as a critical point.

An approach to earthquake prediction based on long-distance correlations has been given by SoRnetTe and SAmmis (1995), who suggested that small and intermediate magnitude earthquakes are associated with the growing correlation length of the regional stress field prior to a large event, with the final event in the cycle being analogous to the critical point of a chemical or magnetic transition. This hypothesis is an extension of the work of VARNES (1989), BUfE and VARNES (1993) and BUFE et al. (1994) who suggested that there is a power-law increase in the regional cumulative Benioff strain release, $S(t)$, before a large event, defined as:

$$
S(t)=\sum_{i=1}^{n(t)} E_{i}(t)^{1 / 2}
$$

where $E_{i}$ is the seismic energy of the $i$-th preshock and $n(t)$ is the number of events at time $t$. BufE and VARNes (1993) proposed the following relation to fit the time variation of the cumulative Benioff strain:

$$
S(t)=A+B\left(t_{c}-t\right)^{m}
$$

where $t_{c}$ is the origin time of the main shock and $A, B, m$ are parameters which can be calculated by the available data. In this relation $A$ is the total Benioff strain including the strain of the main shock. Since the seismic energy can easily be calculated from the earthquake magnitudes in relation (1), data can be used to determine the parameters of relation (2), thus estimating the origin time and the magnitude of the main shock. A major difficulty, however, that one faces is the accurate definition of the preshock (critical) region.

Recently BOWMAN et al. (1998) proposed a procedure to test for accelerating seismicity patterns and to identify regions approaching criticality before all earthquakes with $\mathrm{M}>6.5$ which occurred along the San-Andreas fault system since 1950. To identify the critical region for each of the $M>6.5$ events they developed an optimization algorithm which identified regions of accelerating seismicity by examining the value of the parameter $C$, which is the ratio of the root-mean square error of the power-law fit (relation 2) to the corresponding linear fit error. The circle centered at the main shock epicenter for which $C$ has a minimum value with $m$ being less than 0.8 is considered as the critical region for this main shock.

PAPAZAChOS and PAPAZACHOS (2000a,b) further developed this methodology by considering elliptical areas centered at the main shock epicenters. They confirmed that the dimensions of the elliptical areas scale with the main shock magnitudes 
and found that the preshock times are inversely proportional to strain release rate; high seismicity areas have short preshock times. In their very recent work Papazachos and Papazachos (2001) derived relations between the parameters $A$ and $B$ of relation (2) and other independently determined parameters of the critical region.

A topic which, to the best of our knowledge, has not been extensively addressed is the existence and the identification of the time variation, if any, of the $b$ value of the Gutenberg and Richter (1944) recurrence law, as well as of the parameter $C$ mentioned above, during the preshock time period in the critical region. Although the decrease of $b$ value before a large earthquake is a well known phenomenon (Mogi, 1967; PAPAZACHOS, 1974a), its time variation during the accelerating seismicity period did not attract the attention it deserves. JAUMÉ and SYKeS (1999) investigated the frequency-magnitude distribution of earthquakes during earlier and later periods of several observed accelerating moment/energy release sequences and found that $b$ values were lower in the later periods. TRIEP and SyKES (1997) found a lower $b$ value for events with $\mathrm{M} \geq 7.0$ which occurred in Asia during 1900-1957, than the $b$ value calculated for the same area for the period 1957-1994. They associated this change with the giant Himalayan earthquake in 1950 of $\mathrm{M}=8.6$.

An attempt is made in the present paper to contribute to this topic by studying the behavior of the $b$ value in the preshock (critical) regions of strong main shocks which occurred in the Aegean area. The time variation of the curvature parameter $C$ is also studied.

\section{Data Used}

Seismicity in the broader Aegean area is the highest in the entire western Eurasia. It is mainly expressed by shallow earthquakes with magnitudes reaching 8.0 while intermediate depth earthquakes of the same order of magnitude occur along the southern Aegean subduction. Figure 1 shows an epicenter map of four sets of shallow earthquakes which occurred in Greece and surrounding area during the following time periods: $1850-2000, \quad M \geq 6.0 ; 1911-2000, \quad M \geq 5.2 ; 1950-2000$, $\mathrm{M} \geq 4.5 ; 1981-2000, \mathrm{M} \geq 4.0$. The data come from the catalogue of PAPAZACHOS et al. (2000) and can be found at the following site of IASPEI http://geohazards.cr.usgs.gov/iaspei/europe/greece/the/catalog.txt.

Before we proceed further we believe it is necessary to briefly account of the procedure followed by PAPAZACHOS and PAPAZACHOS (2000a) for the identification of regions in the earth's lithosphere where strain is accelerating before main shocks. They considered elliptical areas centered at the epicenters of 24 strong $(M \geq 6.0)$ shallow main shocks which occurred in the Aegean and surrounding area during 1948-1997. For each case, the azimuth, $z$ (measured clockwise from north), the 


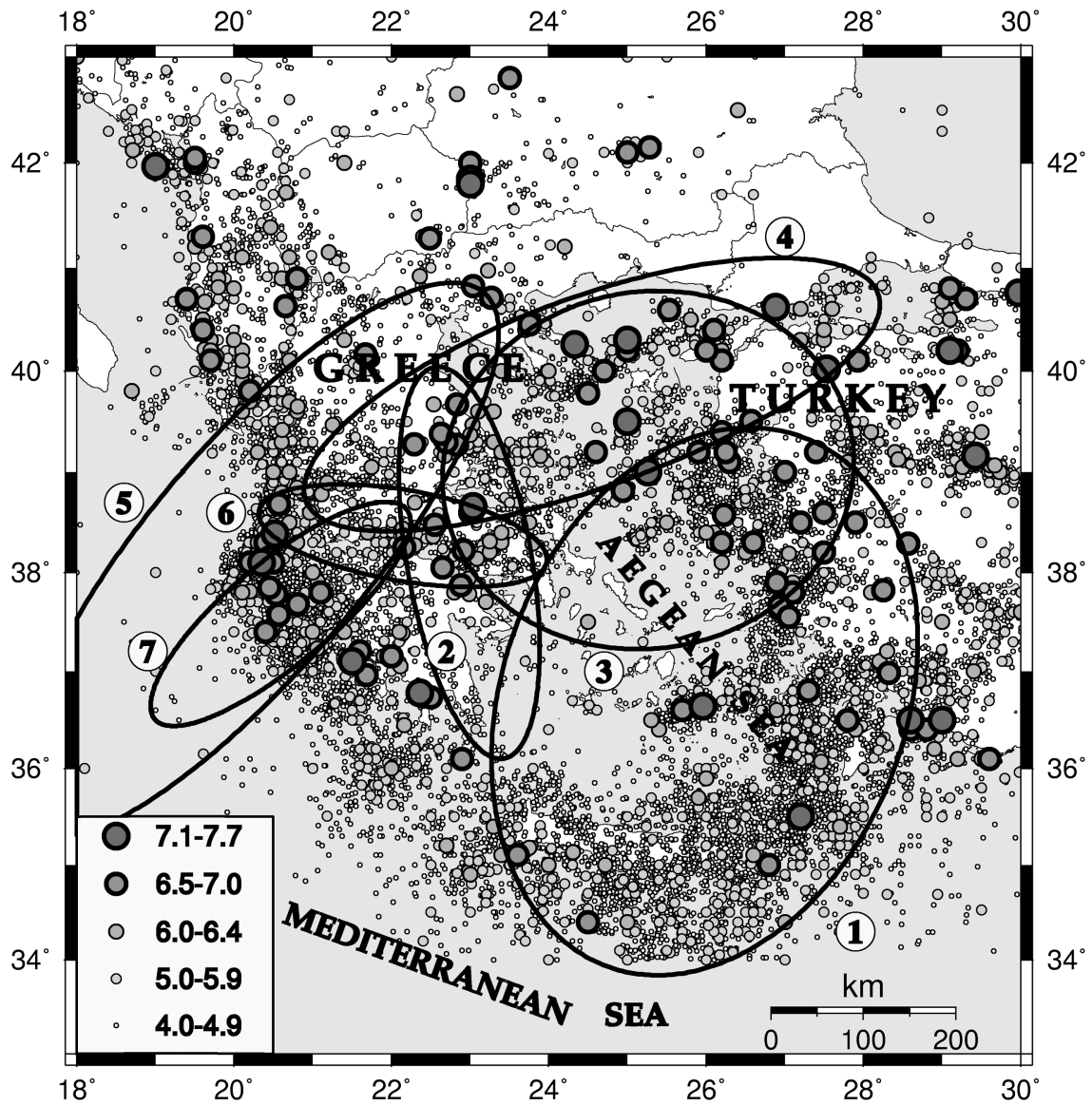

Figure 1

Epicenter map of four sets of shallow earthquakes which occurred in Greece and the surrounding area during the following time periods (PAPAZACHOS et al., 2000): 1850-2000, $\mathrm{M} \geq 6.0 ; 1911-2000, \mathrm{M} \geq 5.2$; 1950-2000, $\mathrm{M} \geq 4.5 ;$ 1981-2000, $\mathrm{M} \geq 4$.0. The elliptical critical regions of the seven main shocks listed in Table 1 are also shown.

ellipticity, $e$, and the large axis, $a$ (in $\mathrm{km}$ ) of the ellipses were allowed to vary. All possible azimuths (in $10^{\circ}$ steps) were examined along with numerous ellipticity values and lengths of the axes of the ellipses. Within each elliptical area defined by a $z-e-a$ combination the cumulative Benioff strain expressed by the relation (1) was calculated as a function of time by using all events (main shock included) which occurred within the area. The calculation was performed for different time periods, $t_{p}\left(=t_{c}-t_{s}\right)$, before the main shock by considering different initiation times, $t_{s}$, since the time when the accelerated seismicity period started, in steps of 1 year. Therefore, the finally examined data sets for each case were those which resulted from all possible earthquake catalogues which were created for each $z-e-a-t_{s}$ combination. 
For each of these data sets the observed cumulative strain variation, $S(t)$, calculated by using relation (1), was fitted by a power-law relation of the form (2), allowing for the determination of parameters $B$ and $m$, as well as the $r m s$ fit error. The same data were fitted by a linear relation and the corresponding errors are also calculated. The elliptical area for which the ratio

$$
C=\frac{\text { power }- \text { law }- \text { fit }- \text { root }- \text { mean }- \text { square }- \text { error }}{\text { linear }- \text { fit }- \text { root }- \text { mean }- \text { square }- \text { error }}
$$

was minimum, was considered as the preshock region of each main shock, as suggested by BOWMAN et al. (1998). This means that when the power law fits better the data, its $r m s$ will be smaller compared to the linear fit $r m s$ and $C$ will be small. Conversely, if the seismicity is increasing linearly, the power-law fit will approximate the linear fit and the parameter $C$ will tend to 1. PApazachos and PAPAzachos (2000a) found, among other results, that all 24 main shocks were preceded by accelerating seismic deformation.

\section{b Value Variation}

In the present work we have studied the time variation of the seismic activity, as it is expressed by the $b$ value, in some of these preshock areas. For this reason we selected those areas with a large enough number of preshocks $(n \geq 100)$, that is, earthquakes which occurred in the preshock period within the area. These elliptical preshock areas are shown in Figure 1. The parameters of the main shocks and the preshock areas associated with them have been extracted from Papazachos and Papazachos $(2000 \mathrm{a}, \mathrm{b})$ and are given in Table 1. For each main

Table 1

Information pertaining to the seven main shocks and their respective preshock areas studied; the first six columns give the main shock parameters (code number, date, origin time, epicentral coordinates, magnitude), the following five columns list the parameters of the preshock areas (preshock time, $t_{p}$, in years, azimuth, $z$, and length, $a$, in $\mathrm{km}$, of the major axis of the ellipse, its ellipticity, $e$ and the critical exponent $m$ of relation (2), while the last two columns give the threshold magnitude, $M_{\min }$, of the preshocks considered as well as their number, $n$ (after PAPAZACHOS and PAPAZACHOS, 2000a)

\begin{tabular}{rcccccccccccc}
\hline No. & Date & $\mathrm{h}: \mathrm{m}: \mathrm{s}$ & $\varphi_{N}^{\circ}$ & $\lambda_{E}^{\circ}$ & $M$ & \multicolumn{1}{c}{$t_{p}$} & $z$ & $a$ & $e$ & $m$ & $M_{\min }$ & $n$ \\
\hline 1 & 1956.07 .09 & $03: 11: 40$ & 36.64 & 25.96 & 7.5 & 33.5 & 20 & 321 & 0.7 & 0.52 & 5.0 & 128 \\
2 & 1981.02 .24 & $20: 53: 37$ & 38.07 & 23.00 & 6.7 & 23.2 & 170 & 222 & 0.95 & 0.33 & 4.5 & 147 \\
3 & 1981.12 .19 & $14: 10: 51$ & 39.00 & 25.26 & 7.2 & 32.0 & 80 & 227 & 0.50 & 0.52 & 4.5 & 526 \\
4 & 1982.01 .18 & $19: 27: 25$ & 39.78 & 24.50 & 7.0 & 13.1 & 70 & 331 & 0.95 & 0.40 & 4.3 & 351 \\
5 & 1983.01 .17 & $12: 41: 31$ & 38.10 & 20.20 & 7.0 & 13.0 & 40 & 391 & 0.95 & 0.70 & 4.5 & 438 \\
6 & 1995.06 .15 & $00: 15: 49$ & 38.37 & 22.15 & 6.4 & 11.5 & 100 & 162 & 0.95 & 0.65 & 4.0 & 244 \\
7 & 1997.11 .18 & $13: 07: 41$ & 37.58 & 20.57 & 6.6 & 13.9 & 50 & 184 & 0.95 & 0.72 & 4.5 & 143 \\
\hline
\end{tabular}


shock all basic parameters are given (date, origin time, epicenter coordinates, magnitude) followed by the parameters of the preshock area (preshock time, $t_{p}$, azimuth, $z$, and length, $a$ [in $\mathrm{km}$ ] of the major axis of the ellipse, and its ellipticity, e) and value of the exponent, $m$, of relation (2). The last two columns give the threshold magnitude, $M_{\min }$, above which preshocks are considered and the numbers, $n$, of the preshocks.

For each preshock area, the $b_{\text {ell }}$ value of the Gutenberg-Richter law was determined by using all preshocks with magnitude, $M \geq M_{\min }$, excluding the main shock. Then, consecutive $b_{i}$ values were calculated by progressively reducing, with a step of one event, the number of the preshocks, starting from the beginning of the preshock period. The last $b_{i}$ value was determined by the last 40 preshocks. To normalize the variation of the $b$ value, the ratio $b_{i, e}=b_{i} / b_{e l l}$ is plotted as a function of time, $t_{i}$, which is the occurrence time of the first event of the remaining preshocks. A constraint imposed on the $b$ value determination was that the magnitude range, $\Delta M$, of the data set was at least 1.5 , because it has been shown that false $b$ value variations (usually larger $b$ values) can be found for a smaller magnitude range (PAPAZACHOS, 1974b).

Figure 2 shows the time variation of the $b_{i, e}$ values for the earthquakes which occurred in the preshock areas listed in Table 1. Dashed lines mark the magnitude range, $\Delta M$, during the computation of these values, which is always kept equal to or larger than 1.5. A decreasing $b$ value trend can easily be observed in all cases, even in those where there is a transient increase of the $b$ values. This increase can be inherently attributed to the procedure followed, since we first determine the $b$ value for the whole data set of each preshock region and then we proceed by omitting earthquakes from the beginning of the preshock period. As a result, when a strong event is excluded from the data set, the $b$ value increases. It can also be attributed to the aftershocks of small main shocks which occurred during the preshock period. Figure 3 shows the time variation of the average $b$ values calculated from all seven cases after reduction to a common time period of 30 years, where a similar decrease of $b$ with time can be clearly seen.

To avoid any bias introduced by using uneven data sets, $b$ values for a moving window of at least 40 preshocks, with step of one preshock, were also calculated for those preshock regions with enough data $(n \geq 200)$ to detect $b$ value variations (regions 3, 4, 5, 6,). Similar constraints, that is, the magnitude range, $\Delta M$, of the data set being at least 1.5, were also imposed on these calculations and their results are shown in Figure 4. It can be observed, as in Figure 2, that changes in the magnitude range result in significant $b$-value variations. However, it can also be observed that during most time periods in which the magnitude range remains stable, the $b$ values exhibit a clear decreasing trend. Figure 5 shows the time variation of the average $b$ values calculated from the four cases presented in Figure 4, after reduction to a common time period of 30 years. A decreasing trend of $b$ with time can easily be observed, similar to Figure 3. 

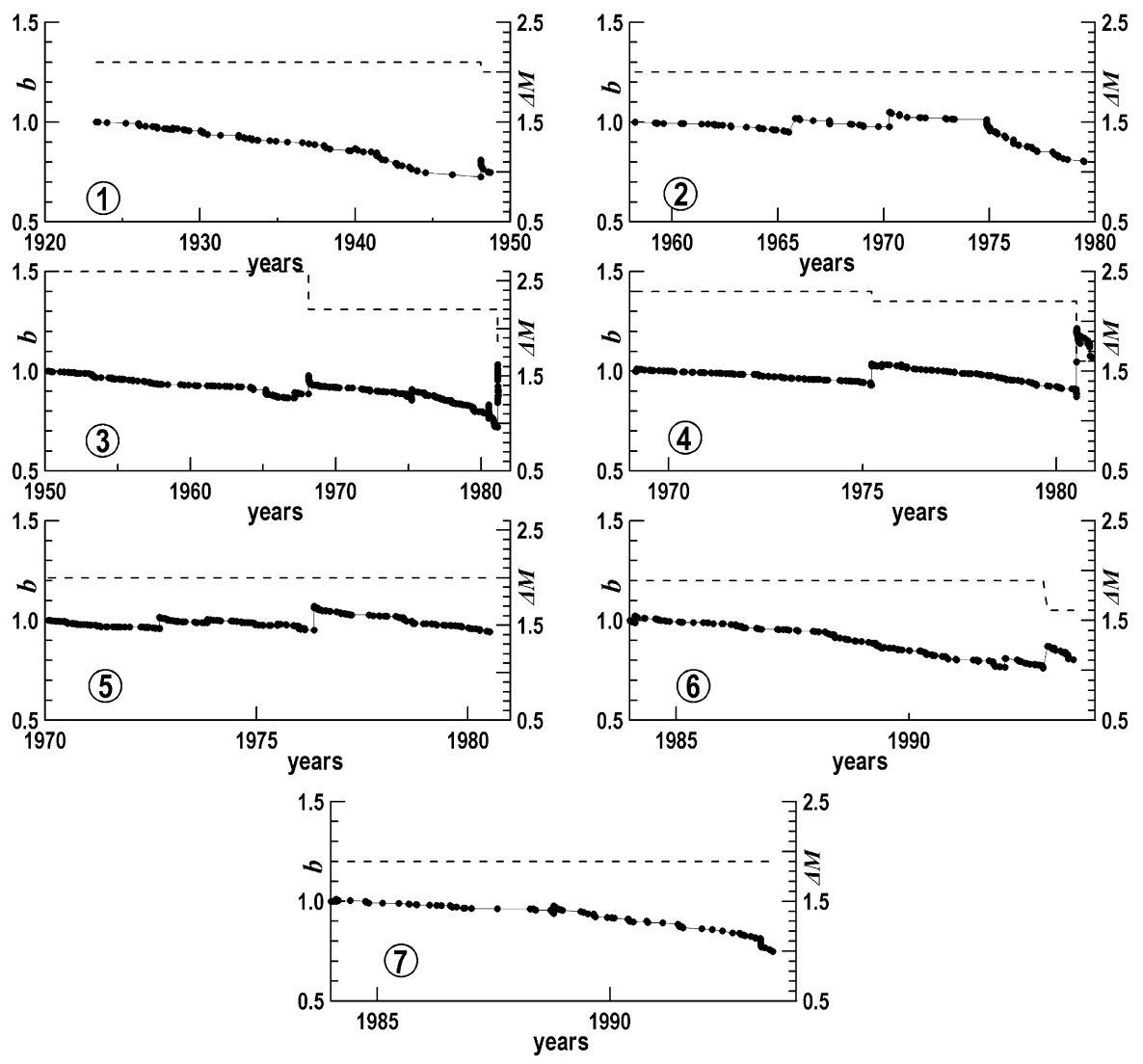

Figure 2

Time variation of the $b_{i, e}$ values for the earthquakes which occurred in the preshock areas listed in Table 1. Dashed lines mark the magnitude range, $\Delta M$, during the computation of these values.

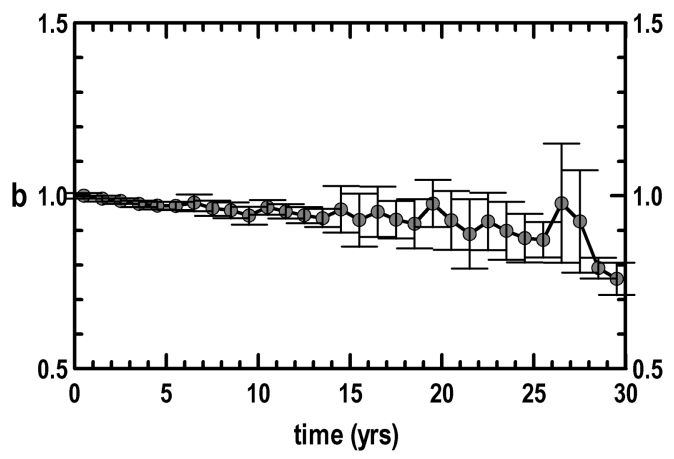

Figure 3

Composite time variation of the mean of all $b_{i, e}$ values (per year) shown in Figure 2, after reduction to a common time period of 30 years. Their standard deviations are also shown. 

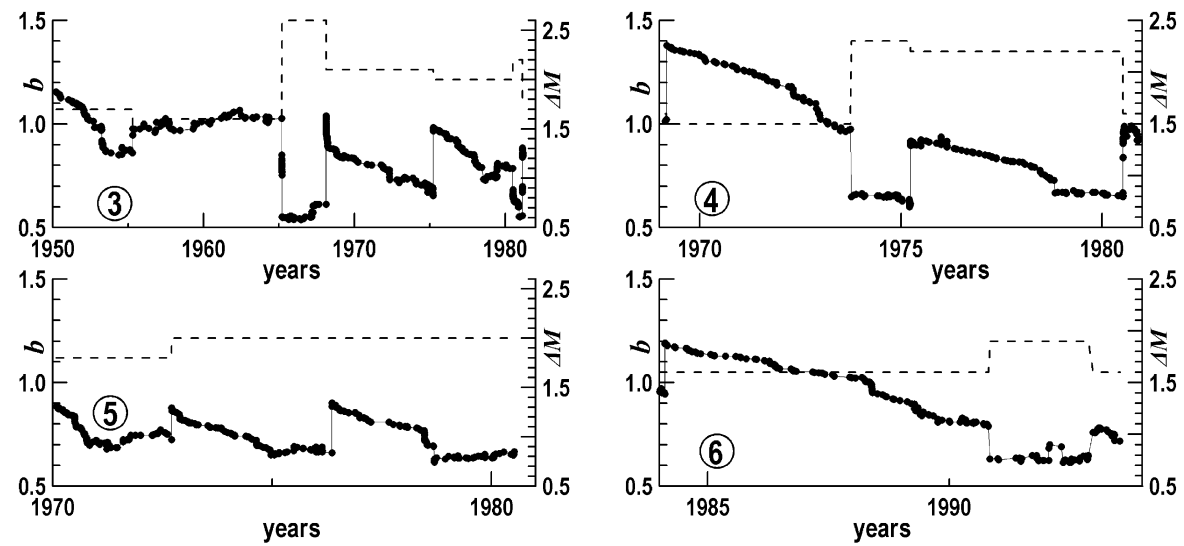

Figure 4

$b$ values for a moving window of at least 40 preshocks, with a step of one preshock, for the preshock areas $3,4,5$ and 6 of Figure 2. Dashed lines mark the magnitude range, $\Delta M$, during the computation of these values.

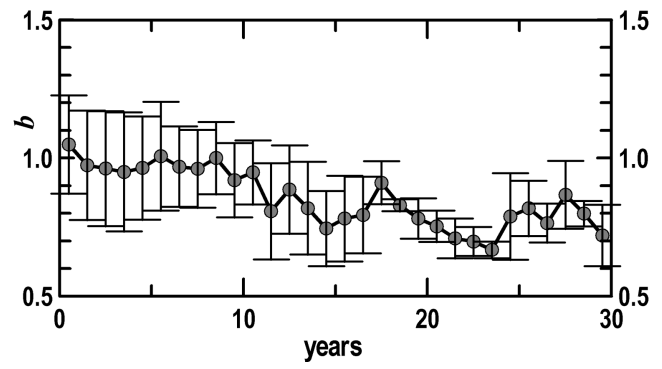

Figure 5

Composite time variation of the mean of all $b$ values (per year) shown in Figure 4, after reduction to a common time period of 30 years. Their standard deviations are also shown.

\section{Value Variation}

In order to seek for any time variation of the $C$ parameter for the preshocks of the critical regions listed in Table 1, the following procedure was adopted: for a certain preshock sequence which preceded a main shock with origin time $t_{c}$ (listed in Table 1, columns $2 \& 3$ ) the first 6 preshocks were considered and were fitted by relation (2). After determining the linear fit for these preshocks, the $C$ parameter was calculated and plotted against the origin time of the 6th event. Thereafter, the next preshock was considered and all calculations were repeated for these seven preshocks with the resulting $C$ value being plotted against the origin time of the 7 th preshock. The procedure was continued until all preshocks were considered.

$C$ values determined by the technique described above are shown in Figure 6. A general decrease of $C$ with time is identified, as we approach the main shock 

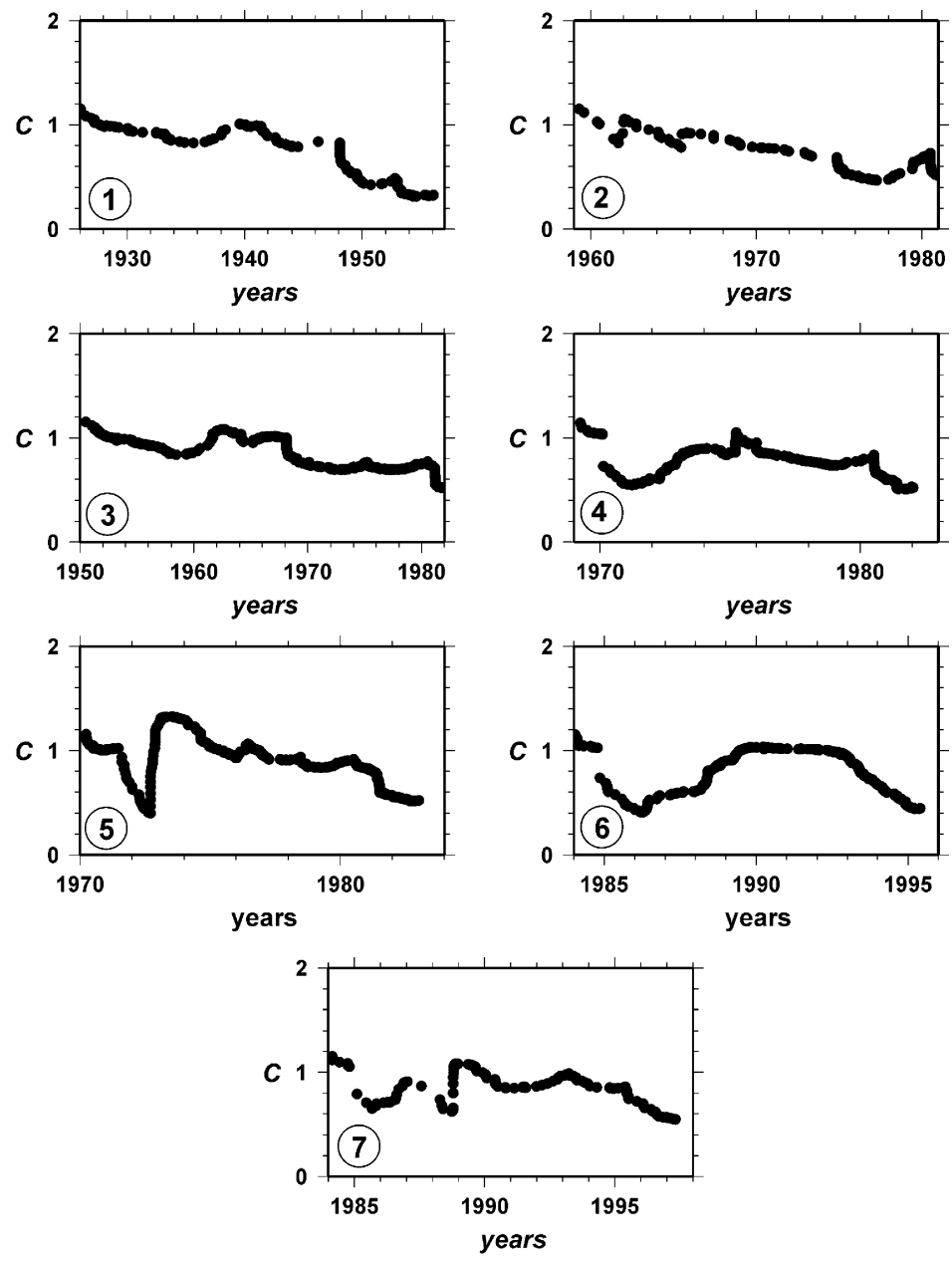

Figure 6

Normalized $C$ values for the seven critical regions of Table 1.

origin time. In all cases the critical exponent $m$ in relation (2) was found to be less than or equal to 0.70 (see Table 1). In Figure 7 the mean values of $C$ from all data shown in Figure 6 and their respective standard deviation are presented, after reduction to a common time period of 30 years. It is observed that during the first half of the preshock period mean $C$ values exhibit fluctuations, however during the second half of the examined period $C$ values are constantly decreasing.

It is of interest to note that $C$ values calculated for all preshock subsets mentioned previously in which the origin time of the last preshock of the subset, instead of the main shock, was considered as $t_{c}$, exhibit a similar decreasing trend as the preshock 


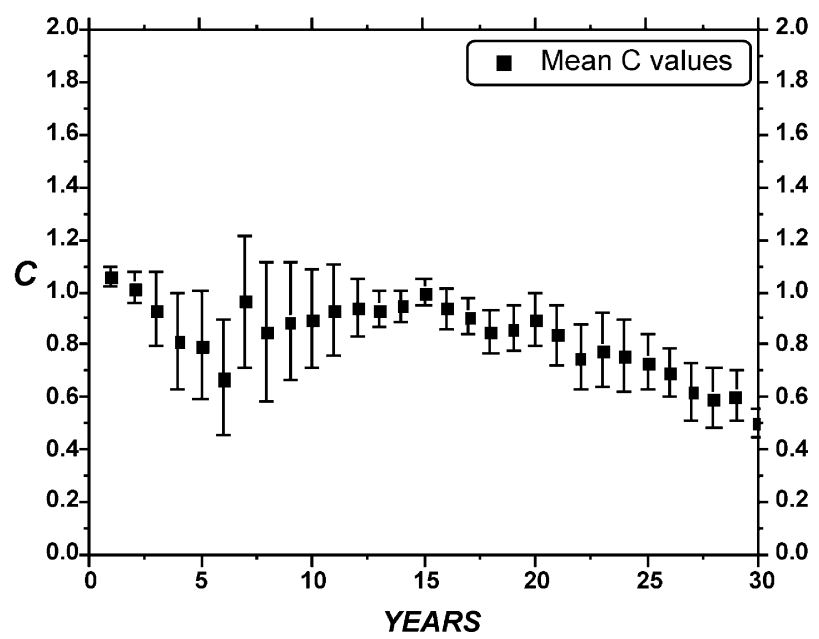

Figure 7

Mean values of parameters $C$ as shown in Figure 6 with their standard deviations.

sequence approaches its culmination (the main shock generation). On the other hand, the time variations of the exponent $m$ of relation (2) showed no consistent trend in the cases examined here.

\section{Discussion and Conclusions}

Statistics on the number of earthquakes as a function of time are usually presented through the GUTENBERG and RICHTER (1944) recurrence law $\log N=a-b M$, with the parameter $b$ measuring the relative number of smaller and larger events in a given period of time. Experimental studies which have shown that the $b$ value of acoustic emissions decrease prior to rock fracture (MogI, 1962; SCHOLZ, 1968) and studies on foreshock and aftershock sequences (PAPAZACHOs et al., 1967; GibOwicz, 1973; MOLCHAN et al., 1999) indicate that changes in $b$ values are inversely related to changes in stress and that the mean fracture size increases as gross failure approaches (Scholz, 1990). Li et al. (1978) studying the $b$ value temporal behavior found a decrease of this value two years before the 1976 Tangshan earthquake.

As $b$ value is a measure of seismicity and stress level, many of the problems inherent in the identification of precursory seismicity patterns also beset methods designed to detect precursory $b$ value variations (REYNERS, 1981). For example, MA (1978) studying $b$-value time variations before several large earthquakes in north China has found that, for small areas around the epicenters of the impending earthquakes, $b$ was decreasing, while for larger areas peak $b$ values 
appeared immediately before the earthquakes. TRIEP and SYKeS (1997) showed that during the period 1900-1957 the seismic activity for earthquakes with $M \geq 7.0$ in Asia was 3.3 times higher than it was for the period 1957-1994 and that during the period of high activity $b$ value was equal to 1.17 in contrast to the $b$ value during the period of low rate $(=2.98)$. They associated this remarkable change with the buildup of stress in the decades prior to the giant 1950 Assam earthquakes and its release at the time of (and perhaps in the ensuing several years) its occurrence. SHIRMAN and Blanter (1999), investigating a mixed hierarchical seismicity model, found a decreasing $b$ value and suggested its potential use as a precursor of strong events.

We have shown that during the accelerating seismic activity period the $b$ value decrease in the preshock area prior to the oncoming main shock. The decrease is more pronounced at the later phase of the accelerating seismicity. Critical factors for such studies are the selection of a critical (preshock) area and the magnitude range of the earthquakes.

Our results are consistent with the observations reported by JAUMÉ and SyKeS (1999) that the rate of occurrence of smaller events does not change during the preshock period although the larger events during the accelerating sequence occur preferentially during the latter half of the sequence; this leads to a progressively decreasing $b$ value.

We have also found that, although the curvature parameter $C$ exhibits fluctuations during the first half of the preshock period, its decreasing trend during the second half of the preshock period suggests that the power law fits better the data than the linear fit, thus implying that the region approaches the critical point (main shock generation). This observation is also important for earthquake prediction purposes.

The qualitative nature of the results precludes their use in estimating the origin time of the oncoming main shock. Rather, they might be used as additional evidence of the approaching failure, since $b$ and $C$ decreasing trends were found to be closely associated with the occurrence time of the oncoming main shock. Further work, however, is needed to confirm the results presented here.

\section{Acknowledgements}

This research was supported by the Earthquake Protection and Planning Organization (E.P.P.O.) program (Project No. 20242 of Res. Committee of A.U.Th). We are grateful to two anonymous reviewers whose comments enhanced this paper and further to clarified certain issues. Thanks are also due to WeSSEL and SMiтh (1995) for their generous distribution of the GMT software used to generate the maps of this study. This is a Department of Geophysics of Aristotle University of Thessaloniki Contribution No. 0565/2001. 


\section{REFERENCES}

Bowman, D. D., Oulllon, G., Sammis, C. G., Sornette, A., and Sornette, D. (1998), An Observational Test of the Critical Earthquake Concept, J. Geophys. Res. 103, 24,359-24,372.

Bufe, C. G. and Varnes, D. J. (1993), Predictive Modelling of Seismic Cycle of the Great San Francisco Bay Region, J. Geophys. Res. 98, 9871-9883.

Bufe, D. G., Nishenko, S. P., and Varnes, D. J. (1994), Seismicity Trends and Potential for Large Earthquakes in the Alaska-Aleutian Region, Pure Appl. Geophys. 142, 83-99.

Fedotov, S. A. (1968), The Seismic Cycle, Quantitative Seismic Zoning, and Long-term Seismic Forecasting. In Seismic Zoning of the USSR (ed. Medvedev, S.) Nauka, Moscow, 133-166.

Gibowicz, S. J. (1973), Variation of the Frequency Magnitude Relation during Earthquake Sequences in New Zealand, Bull. Seismol. Soc. Am. 63, 517-528.

Gutenberg, B. and Richter, C. F. (1944), Frequency of Earthquakes in California, Bull. Seismol. Soc. Am. 34, 185-188.

Jaumé, S. C. and Sykes, L. R. (1999), Evolving Towards a Critical Point: A Review of Accelerating Seismic Moment/Energy Release Rate Prior to Large and Great Earthquakes, Pure Appl. Geophys. 155, 279-306.

Karakaisis, G. F., Kourouzidis, M. C., and Papazachos, B. C. (1991), Behavior of the Seismic Activity during a Single Seismic Cycle. International Conference on Earthquake Prediction: State-of-the-art, Strasbourg, France, 15-18 October 1991, 47-54.

KeILIs-BoroK, V. I. (1990), The Lithosphere of the Earth as a Nonlinear System with Implications for Earthquake Prediction, Rev. Geophys. 38, 19-34.

Keilis-Borok, V. I., Knopoff, L., Rotwain, I. M., and Allen, C. R. (1988), Intermediate-term Prediction of Occurrence Times of Strong Earthquakes, Nature, 335, 690-694.

Knopoff, L., Levshina, T., Keilis-Borok, V. J., and Mattoni, C. (1996), Increased Long-range Intermediate-magnitude Earthquake Activity Prior to Strong Earthquakes in California, J. Geophys. Res. 101, 5779-5796.

Li, Q. L., Chen, J. B., Yu, L., and Hao, B. L. (1978), Time and Space Scanning of the b-value: A Method for Monitoring the Development of Catastrophic Earthquakes, Acta Geophys. Sinica 21, 101-125.

MA H. C. (1978), Variations of the b-values Before Several Large Earthquakes Occurred in North China, Acta Geophys. Sinica 21, 126-141.

Mogi, K. (1962), Study of Elastic Shocks Caused by the Fracture of Heterogeneous Materials and their Relation to Earthquake Phenomena, Bull. Earthquake Res. Inst., Univ. of Tokyo, 40, 125-173.

Mogi, K. (1967), Earthquakes and Fractures, Tectonophysics 5, 35-55.

Mogi, K. (1969), Some Features of the Recent Seismic Activity in and Near Japan, 2, Activity before and after Great Earthquakes, Bull. Earthquake Res. Inst., Univ. of Tokyo, 47, 395-417.

Mogi, K. (1977), Seismic Activity and Earthquake Predictions, Proc. Symp. On Earthq. Pred. Res., 203-214 (in Japanese).

Mogi, K. (1981), Seismicity in Western Japan and Long-term Earthquake Forecasting. In Earthquake Prediction, An International Review (eds. D. W. Simpson and P. G. Richards), Maurice Ewing Series 4, AGU, 43-51.

Molchan, G. M., Kronrod, T. L. and Nekrasova, A. K. (1999), Immediate Foreshocks: Time Variation of the $b$ Value, Physics Earth Planet. Inter. 111, 229-240.

Papazachos, B. C. (1974a), On Certain Aftershock and Foreshock Parameters in the Area of Greece, Ann. Di. Geofisica 27, 497-515.

Papazachos, B. C. (1974b), Dependence of the Seismic Parameter b on the Magnitude Range, Pure Appl. Geophys. 112, 1059-1065.

Papazachos, B. C. and Papazachos, C. B. (2000a), Accelerated Preshock Deformation of Broad Regions in the Aegean Area, Pure Appl. Geophys. 157, 1663-1681.

Papazachos, C. B. and Papazachos, B. C. (2000b), Observations of Preshock Seismic Deformation in the Aegean Area and Earthquake Prediction, XXVII General Assembly of the ESC, Lisbon, 10-15 September 2000, 301-305.

Papazachos, C. B. and Papazachos, B. C. (2001), Precursory Seismic Deformation in the Aegean Area, Annali di Geophysica, 44, 461-474. 
Papazachos, B. C., Delibasis, N., Liapis, N., Moumoulidis, G., and Purcaru, G. (1967), Aftershock Sequences of Some Large Earthquakes in the Region of Greece, Ann. di Geofisica 20, 1-93.

Papazachos, B. C., Comninakis, P. E., Karakaisis, G. F., Karakostas, B. G., Papaioannou, Ch. A., PAPAZAChos, C. B., and Scordilis, E. M. (2000), A Catalogue of Earthquakes in Greece and Surrounding Area for the Period 550BC-1999, (Publication of the Geoph. Lab., Univ. of Thessaloniki).

Raleigh, C. B., Sieh, K., Sykes, L. R., and Anderson, D. L. (1982), Forecasting Southern California Earthquakes, Science 217, 1097-1104.

ReYners, M. (1981), Long-and Intermediate-term Seismic Precursors to Earthquakes-state-of-the-art. In Earthquake Prediction, An International Review (eds. D. W. Simpson and P. G. Richards), Maurice Ewing Series 4, AGU, 333-347.

Scholz, C. H. (1968), The Frequency-magnitude Relation of Microfracturing in Rock and its Relation to Earthquakes, Bull. Seismol. Soc. Am. 58, 399-415.

Scholz, C. H. (1988), Mechanisms of Seismic Quiescence, Pure Appl. Geophys. 126, 701-718.

Scholz, C. H., The Mechanics of Earthquakes and Faulting (Cambridge Univ. Press, New York, 1990) 439 pp.

Shirman, M. G. and Blanter, E. M. (1999), Mixed Hierarchical Model of Seismicity: Scaling and Prediction, Physics Earth Planet. Inter. 111, 295-303.

Sornette, A. and Sornette, D. (1990), Earthquake Rupture as a Critical Point. Consequences for Telluric Precursors, Technophysics 179, 327-334.

Sornette, D. and Sammis, C. G. (1995), Complex Critical Exponents from Renormalization Group Theory of Earthquakes: Implications for Earthquake Predictions, J. Phys. I. France 5, 607-619.

Sykes, L. R. and JAume, S. (1990), Seismic Activity on Neighboring Faults as a Long-term Precursor to Large Earthquakes in the San Fransisco Bay Area, Nature 348, 595-599.

Tocher, D. (1959), Seismic History of the San Fransisco Bay Region, Calif. Div. Mines Spec. Rep. 57, 3948.

Triep, E. G. and SyKes, L. R. (1997), Frequency of Occurrence of Moderate to Great Earthquakes in Intracontinental Regions: Implications for Changes in Stress, Earthquake Prediction, and Hazards Assessments, J. Geophys. Res. 102, B5, 9923-9948.

VArnes, D. J. (1989), Predicting Earthquakes by Analyzing Accelerating Precursory Seismic Activity, Pure Appl. Geophys., 130, 661-686.

Wessel, P. and Smith, W. (1995), New Version of the Generic Mapping Tools, EOS Trans. Amer. Geophys. U., 76, 329.

(Received August 8, 2000, accepted November 27, 2001)

(20) To access this journal online:
(20) http://www.birkhauser.ch 